\title{
L'erotisme a les cançons d'alguns trobadors
}

\section{Gérard Gouiran}

Parlar de la presència d'Eros a la lírica occitana, encara que em proposi limitar-me a l'obra d'un nombre força reduït de trobadors, pot semblar una empresa desmesurada. No cal dir que l'erotisme ocupa un lloc central en la problemàtica de la fin'amor, que configura el tema per excellència de les cansos trobadoresques. Per subratllar la transcendència del tema, em permetré d'afegir una boutade.

Es podria dir que una de les revolucions introduïdes pels trobadors és, sens dubte, la substitució de l'Eros (o Amor en la tradició llatina) de l'antiguitat, representat al costat de la seva mare Afrodita (la Venus Ilatina) com un jovenet, d'edat variable entre la infància i l'adolescència, per una deessa, Amor. I és important recordar que en les llengües gal|loromàniques medievals la paraula «amor» és femenina, fet que, evidentment, no deixarà d'introduir canvis en la concepció de l'erotisme. El gènere gramatical del mot propicia, per exemple, la confusió de la deessa amb la dona estimada.

Seria temptador abordar la qüestió que ens ocupa a través de l'antologia / trovatori licenciosi del

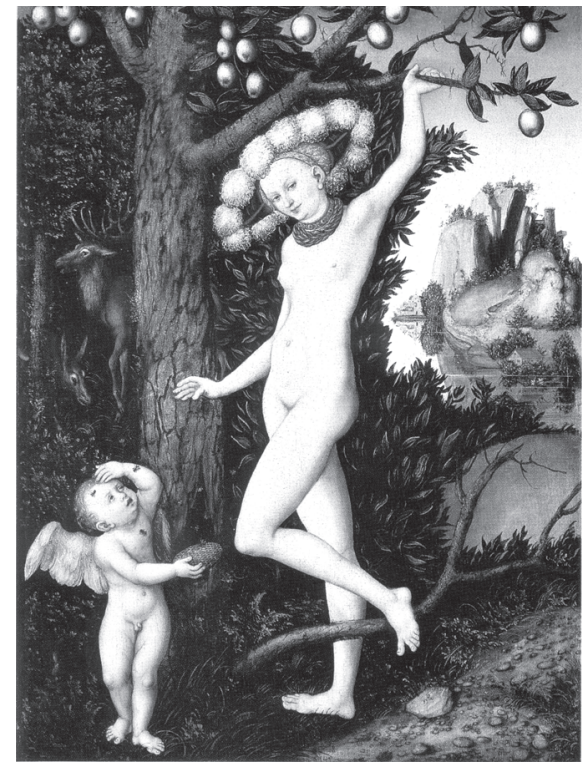

Venus i Cupido picat per les abelles (Lucas Cranach el Vell, National Gallery, Londres).

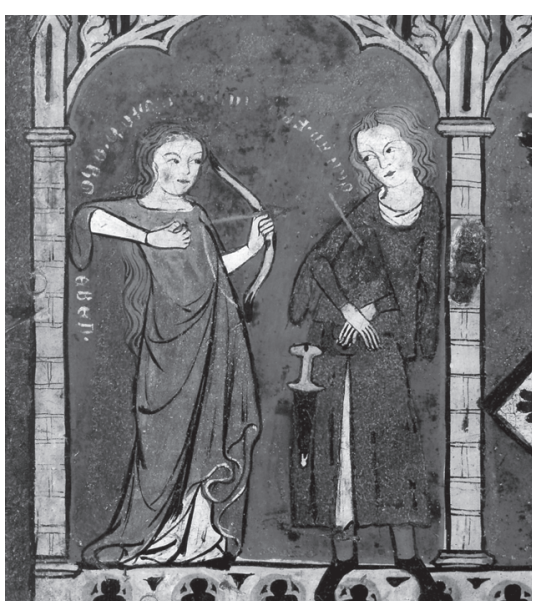

La dama (o Amor) fereix l'enamorat (The Cloisters, Nova York). malaguanyat Giuseppe Sansone (1992), però la lectura ens mostra ben aviat la gran distància que pot separar l'erotisme del capteniment llicenciós. El primer trobador, Guilhem IX d'Aquitània, ja ens en forneix exemples evidents. Pensem al vessant més cràpula de Guilhem al fabliau del gat ros,' amb els cèlebres versos «Tant las fotei com auziretz: / cent e quatre vinz e ueit vetz» ( $V$, vv. 79-80) [Fixeu-vos quantes vegades me les vaig cardar: cent vuitanta-vuit vegades], o a les queixes que posa en boca de la dama, un xic frustrada per les insuficiències d'aquest amant tan pretensiós: «Don, vostre datz son menuder. / Et ieu revit vos a dobler!» (VI, vv. 5I-52) [-Senyor, els vostres daus són petits. -Doncs, jo us repto a tornar a començar!] La distància amb els elements pròpiament eròtics, al meu entendre, és considerable. Vegeu, com a exemple de l'expressió de l'erotisme pròpiament dit a l'obra del nostre comte d'Aquitània, el prec següent:

Enquer me lais Dieus viure tan c'aja mas manz soz so mantel! (X, vv. 23-24)

[Tant de bo Déu em deixi viure fins que pugui posar les mans sota el seu mantell!]

I. Cito l'obra de Guilhem d'Aquitània segons Bec (2004) 


\section{El mantell de la dama}

Cal remarcar que aquest erotisme discret dels tocaments secrets sota el mantell gaudirà d'una llarga vida a la lírica occitana, des del mateix poema del gat ros ja citat: «La una.m pres sotz son mantel, / menet m'en sa cambra al fornel» ( V, vv. 37-38) [Una em va prendre sota el seu mantell i em va dur fins a la seva cambra, prop de la llar de foc]. Perdura fins a l'època final del trobar, amb Bonifaci de Castellana, que en el seu ardor viril iguala la guerra i l'amor, expressant el que en podríem dir un Eros bèllic:

$$
\begin{aligned}
& \text { E ja no.m trobares lasat } \\
& \text { q'ieu non fas'asaut e cenbel } \\
& \text { e non abraz sout son mantel } \\
& \text { donna ab gras cors e delgat } \\
& (\text { I, vv. 46-49) }
\end{aligned}
$$

[I mai no em trobareu tan cansat que no emprengui assalts i combats, o que no abraci una dama de cos menut i rodonet sota el seu mantell]
El mantell de la dama, al meu parer, no fa altra cosa que aixoplugar la parella d'amants de les mirades, com pretén Arnaut Daniel:

\begin{abstract}
ans volgui mais penre fin aur qu'eram
lo jorn que ieu e midons nos baizem

e.m fetz escut de son bel mantel endi, que lauzengier fals, lengua de colobra, non o visson don tan mals motz escampa

$\left(\right.$ I, vv. 20-24) ${ }^{3}$
\end{abstract}

[Vaig preferir prendre l'or fi que el coure el dia que jo i la meva dama ens besàrem i ella em va fer un escut amb el seu bell mantell de color indi, per tal que els falsos llagoters, llengües de serp, no poguessin veure allò que origina tantes xafarderies]

D'altra banda, també podríem arribar a pensar que el mantell protegeix l'amant, però no de les mirades externes sinó de la visió del cos nu de la dama, permetent-li el contacte però evitant un enlluernament que potser no podria resistir.

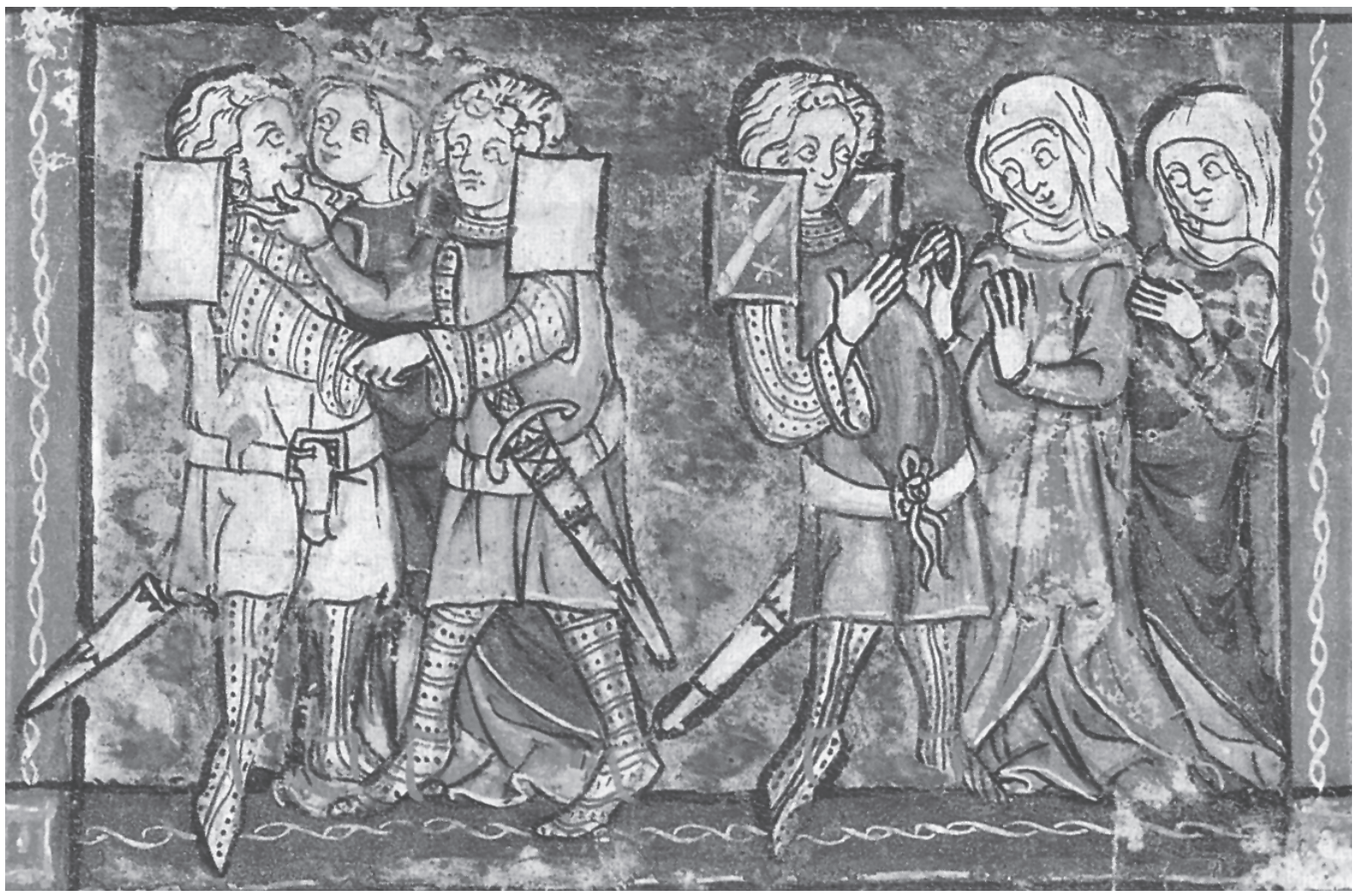

Tocaments clandestins dels amants: el primer petó de Lancelot i la reina Ginebra (Lancelot-Graal, British Library, Londres). 


\section{La dama despullada}

Sota la forma paròdica de la descriptio puellae, podem trobar evidentment descripcions del cos femení que no en tenen prou amb parlar del rostre o jugar amb metàfores. És el cas de la cançó següent, d'atribució dubtosa a Bertran de Born:

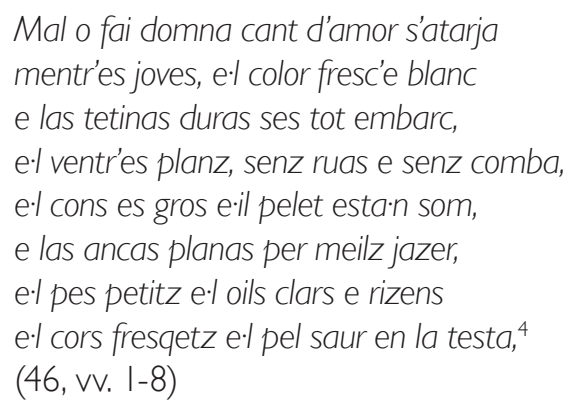

[Una dona fa mal fet quan tarda a estimar mentre és jove, amb la pell fresca i blanca, els pits ferms i durs, i el ventre pla, sense arrugues ni plecs, i el cony és gros i cobert de pelets, les anques planes per jeure millor, els peus petits, els ulls clars i riallers, el cos fresc i, sobre el cap, el cabell daurat.]

El senyor d'Autafort ha sabut evocar perfectament unes fantasies que han fet escriure ratlles ben estranyes als comentaristes més assenyats. Els versos següents, per exemple, els ha desenfrenat la libido de la manera més peculiar:

\section{Rassa, domn'ai qu'es fresqu'e fina, cuenda e gaia e mesquina: pel saur, ab color de robina, blanca per cors com flors d'espina, coude mol, ab dura tetina, e sembla conil per l'esquina; $(1, v v .12-17)$}

[Rassa, tinc una dama que és fresca i fina, amable, alegre i jove, amb els cabells rossos, de color de robí, blanca de cos com una flor d'espí, els colzes suaus, els pits durs i una esquena que sembla de conill]

Al meu parer, l'erotisme no resideix tant en aquestes temptatives de descripcions del cos, sinó més aviat en el pas del vestit al nu. Pierre Bec té molta raó quan exclama que «Podríem escriure tot un article sobre el despullar-se de la dama en l'obra dels trobadors!’..5

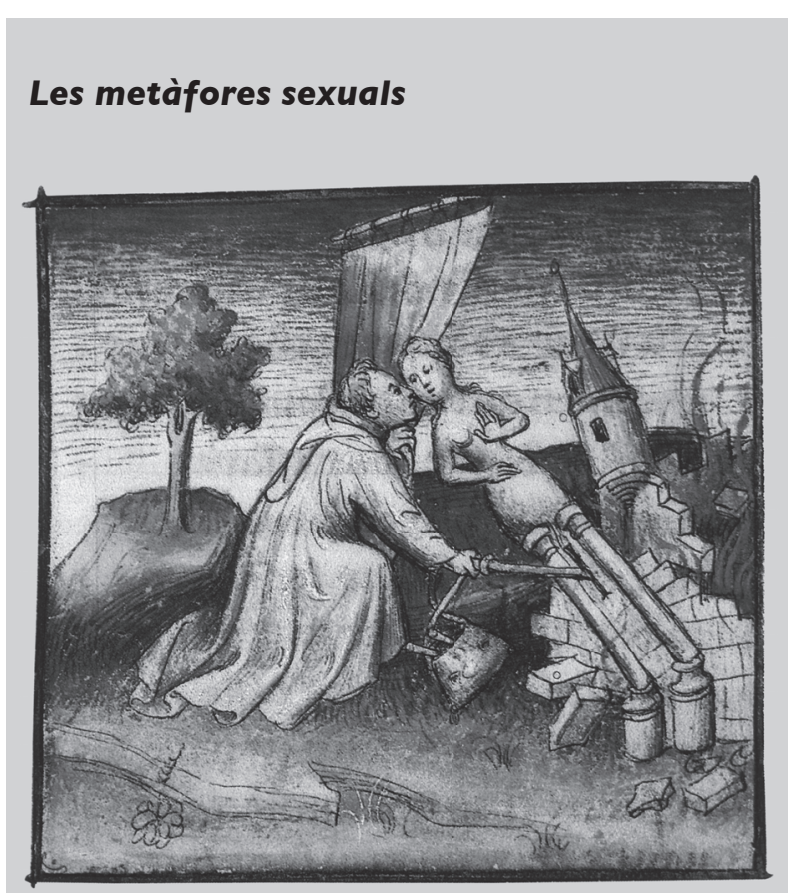

L'enamorat entra al santuari (Roman de la Rose, Biblioteca universitària, València).

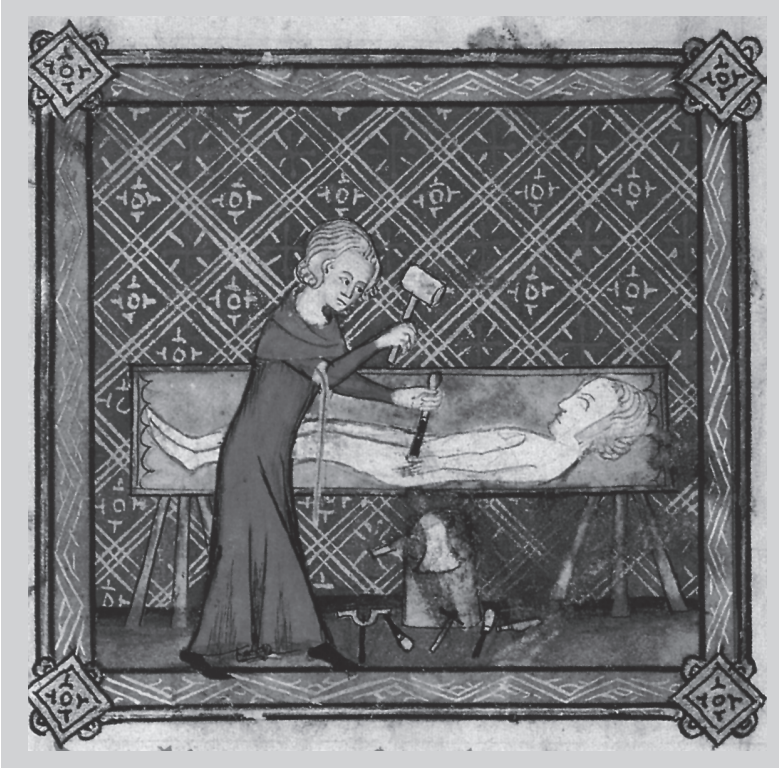

Pigmalió esculpeix la seva enamorada (Roman de la rose, Bibliothèque royale, Brusselles).

4. Les cites de Bertran de Born provenen de Gouiran (1989). 5. Vegeu Bec (1992: 19), que forneix un gran nombre d'exemples. 
De fet, la felicitat suprema del trobador resideix en el fet que la dama es mostri o, millor encara, s'exhibeixi (evidentment, en la imaginació del trobador). Per a Bernart de Ventadorn cap plaer podria superar l'emoció extàtica de ser admès a la cambra on la dama es despulla:

Mal o fara si no.m manda
venir lai on se despolha
$\left(29\right.$, vv. 29-30) ${ }^{6}$

[Farà mal fet si no m'ordena que vingui on ella es despulla]

Oencara:

Res de be no'n es a dire, ab sol c'aya tan d'ardit c'una noih lai o.s despolha me mezes en loc aizit $(19, \mathrm{vv} .4 \mathrm{I}-44)$

[No li manca cap qualitat, només que sigui tan agosarada que, una nit, em dugui en aquell $\|$ oc tan agradable, allà on es despulla]

Vegem-ne un darrer exemple:

E ja no.m volh mais d'a sos pes mover tro per merce.m meta lai o.s despolha (7, vv. 4l-42)

[l ja no em voldré moure mai més dels seus peus fins que per pietat em dugui allà on es despulla]

Podríem afegir aquí els versos d'Arnaut Daniel on tria aquest motiu per elaborar una perífrasi que designa la seva dama: «De part Nil entro c'a Sanchas / genser no.s vest ni.s despuelha» (I2, vv. 36-37) [Des del Nil fins a Saintes, no n'hi ha cap de més bella que es vesteixi i es desvesteixi]

Convé destacar, en tots els exemples presentats, que el sintagma recurrent que converteix la cambra de la dama en un lloc d'exhibició del seu cos es presenta sempre en un futur o en l'eventualitat d'un subjuntiu.

El motiu es desenvolupa a l'obra de Bernart de Ventadorn sobretot en forma de somni, i en particular durant les nits cruels on el trobador, separat de la dama, no pot agafar el son i es lamenta en fórmules com ara «Las! mos cors no dorm ni pauza» (27, v. 45) [Ai las! el meu cos no dorm ni reposa] o «Qu'eu no dorm mati ni ser» $(33, v .9)$ [Perquè no dormo al matí ni al vespre]. I Bernart s'exclama encara: «E la noih no posc pauzar / ni:m pren talans de dormir, / tan es grail'et eschafida» (43, vv. 17-19) [Durant la nit no puc reposar ni em venen ganes de dormir, de tan com ella és menuda i esvelta].

Trobem també un passatge on la visió ritual de la dama que es despulla cedeix irònicament el lloc a la de l'amant, com a prèvia d'una llarga vetlla: «Be sai la noih, can me despolh / el leih qu'eu no dormirai re»» (24, vv. 17-18) [A la nit, quan em despullo, sé ben bé que al meu llit no hi aclucaré l'ull]. El motiu és evident, qualsevol altre llit que no sigui el de la dama serà un instrument de tortura amorosa:

Tota noih me vir e.m lansa

desobre l'esponda,

plus trac pena d'amor

de Tristan l'amador.

$(4, v v .43-46)$

[Tota la nit tomba que gira sobre el llit, pateixo més per amor que Tristany, l'enamorat]

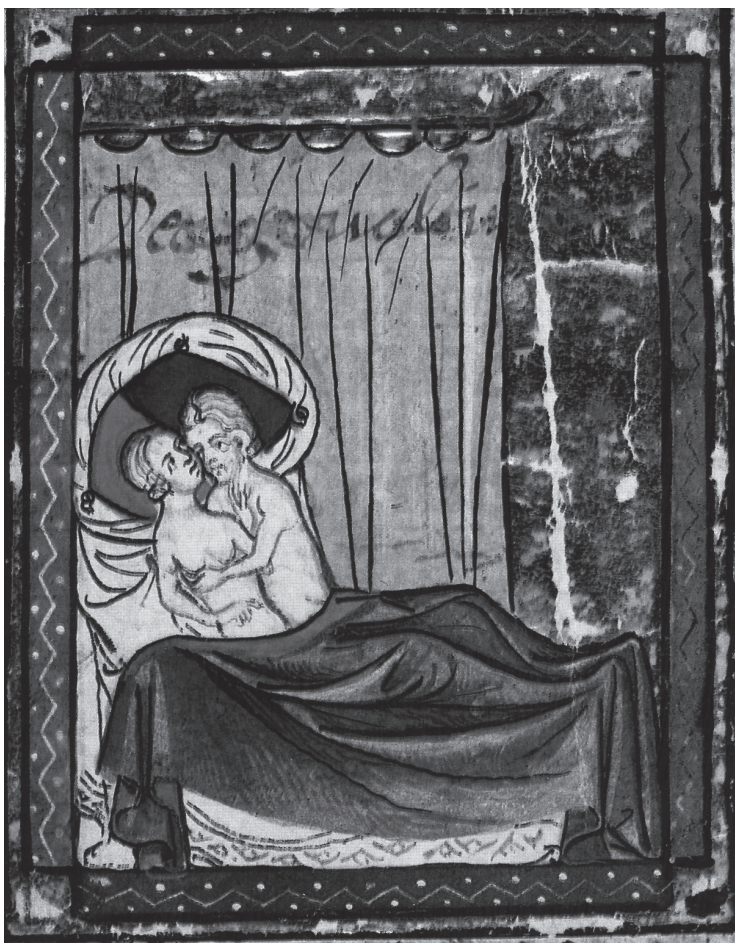

La consumació de l'amor al llit (Roman de la rose, British Library, Londres).

6. Les citacions de Bernart de Ventadorn s'han extret de Lazar (1966). 
Perquè de la cambra de la dama, aquest lloc que Bernart qualifica de paradís, no en sabem res més que la presència d'aquest llit, merament simbòlic de l'amor físic. No veiem mai l'amant traspassant la porta d'aquest paradís. Només Guilhem IX ens parla de la dificultat del passatge, que ell aconsegueix de fer sota una doble protecció: no només porta una disfressa de pelegrí (va «a tapi», el mantell del pelegrí), sinó que per aconseguir entrar a la cambra encara s'ha d'amagar, com hem vist, sota el mantell d'una de les dames (una altra vegada un mantell!). Per als trobadors menys «realistes»que Guilhem, valdria la pena fer la llista de tots els artificis gramaticals que permeten franquejar, almenys a la seva imaginació, el llindar prohibit: des del subjuntiu, que els permet de només concebre mentalment l'acció, a totes les diverses formes del condicional.

\section{Més enllà del Ilindar}

Però, un cop el somni o les concessions gramaticals han permès d'entrar en aquest sancta sanctorum, Iloc sagrat entre els sagrats, ¿com continua l'aventura? Seguint en l'obra de Bernart de Ventadorn, en primer lloc podem trobar l'expressió menys compromesa, una abraçada de sentit força ambigu: «e-m fezes dels bratz latz al col» (19, v. 45) [i que em faci amb els seus braços un llaç al voltant del coll]. La imatge deixa força camp per córrer a la interpretació, és a dir, a l'esperança, com veiem en un altre poema de Bernart: «Midons prec no.m lais per chastic [...] que no.m sent'entre sos bratz.» (6, vv. 33-36) [Prego a la meva dama que, per culpa de les amonestacions que rep, no deixi de sentir-me entre els seus braços.]

Altres cops detalla el context d'aquesta abraçada -el xantatge de la seva mort imminent autoritza totes les audàcies...-, tot precisant si va precedida de carícies, a les quals s'hi poden afegir petons:

\footnotetext{
Ara cuit qu'enn morrai

del dezirer que.m ve

sil bela lai on jai

no m'aizis pres de se

qu'eu la manei e bai

et estrenha vas me

so cors blanc, gras e le.

(I8, vv. 30-36.)
}

[Ara mateix penso que estic a punt de morirme del desig que em ve si la bella no macull al seu costat, allà on jeu, perquè l'acariciï, la besi i estrenyi el seu cos blanc, grassonet i suau contra el meu.]

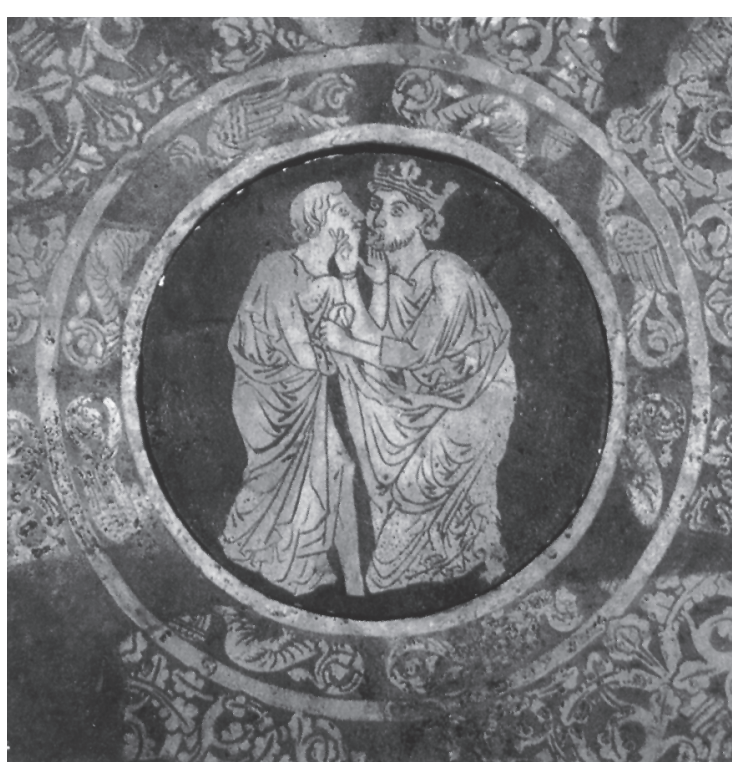

Osculum feudal entre Tristany i el seu oncle Marc (British Museum, Londres).

Gràcies a la complicitat del condicional, el mateix Bernart, tot convertint-se en mag, aconsegueix dotar el petó d'una fogositat que fa ben difícil de reconèixer-hi una transposició de l'osculum de l'homenatge feudal:

e baizerallh la bocha en totz sens,

si que d'un mes i paregra lo sens

(20, vv. 39-40)

[I li faré un petó a la boca en tots sentits, de manera que s'hi veurà la marca durant un mes]

Ens hem allunyat força de la fin'amor amb un petó d'una violència gairebé sàdica, que vol imposar sobre la dama un segell de propietat, digne del marit gelós. Curiosament, aquest petó aconseguirà exposar públicament la marca de l'amant, davant dels ulls d'un públic que haurà d'haver estat prèviament sotmès a un encanteri per tal que no comprengui el sentit d'aquesta marca tan visible.

No és pas l'única vegada que veiem l'homenatge feudal a la base d'un acte amorós que, en canvi, el prolonga i el transmuta profundament: 
Mal o fara, si no.m manda

venir lai on se despolha,

qu'eu sia per sa comanda

pres del leih, josta l'esponda

e.th tragalls sotlars ben chaussans

a genolhs e umilians,

silth platz que sos pes me tenda.

(29, vv. 29-35)

[Farà mal fet si no m'ordena que vingui on ella es despulla, de manera que jo sigui, per manament seu, prop del llit, ben al costat, i que li tregui les sabates que la calcen tan bé, de genolls, humilment, si a ella li plau d'oferir-me els peus.]

Com podem estar-nos de llegir aquesta escena, on s'expressa una dominació tan extrema per part de la dama, com una mena d'estranya cerimònia fetitxista, on la submissió absoluta es bar-reja amb un desig encara per satisfer? Assistim als preliminars d'un erotisme profund, marcat per la proximitat del llit, símbol de la satisfacció del desig, «pres del leih, josta l'esponda»: una proximitat que resta però a una distància que no se sap si mai se salvarà. Aquesta distància només existeix, però, al terreny amorós, perquè la transgressió social es combina amb la transgressió que suposa l'acte de despullar-se, encara més si tenim en compte la gran importància que el vestit tenia a l'Edat Mitjana com a marcador social.

A la lírica dels trobadors recorre la idea, convertida en lloc comú, que l'amor aboleix la distància entre

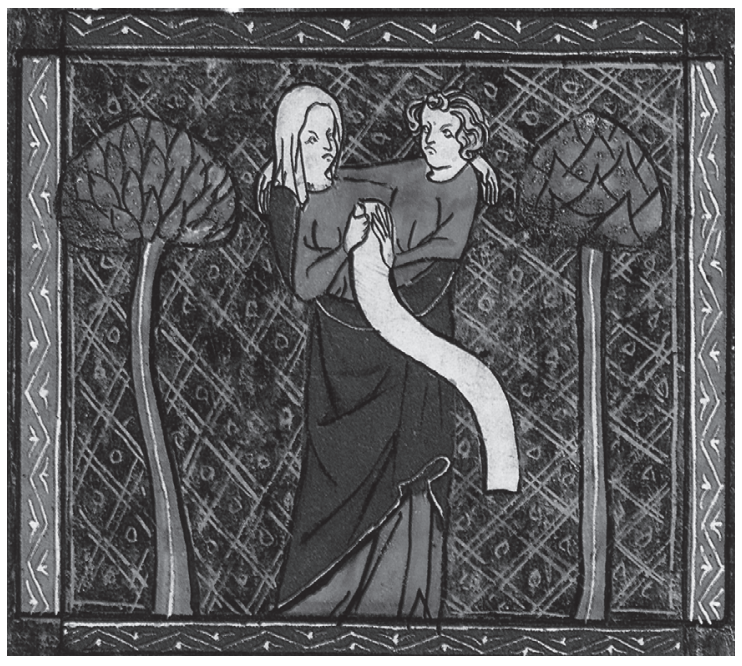

Els amants convertits en un (Ars d'Amour, Bibliothèque royale, Brussel-les). els amants. És doncs accidental que després d'haver parlat del cos nu (o millor, despullat) de la dama, Bernart proposi una mena de definició de l'amor que consistiria a contemplar la seva bellesa «si c'amdui cominal / mezuressem egal»»? L'expressió (literalment, «de manera que els dos, iguals, mesuréssim el mateix») ha presentat problemes tant als copistes medievals com als traductors moderns. Potser seria menys difícil d'interpretar-la si pensem en la idea que la nuesa dels amants els situa en peu d'igualtat (tot i que la de l'home ni s'esmenti).

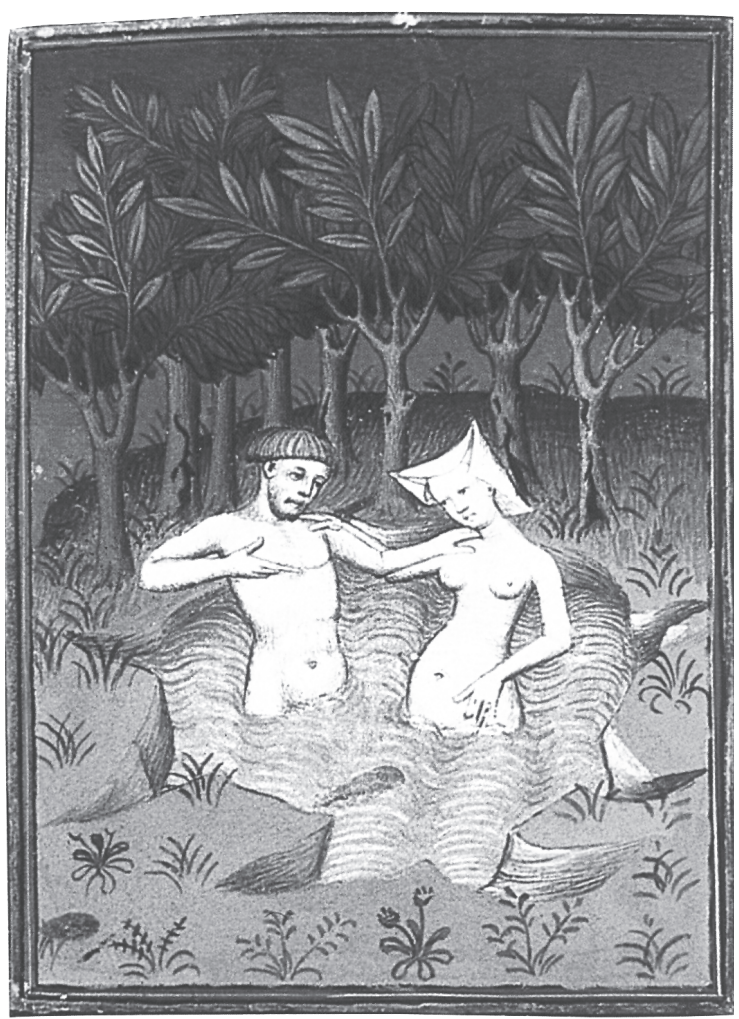

Els amants nus, al bany, amb una pell ostensiblement blanca (British Library, Londres).

\section{El cos Iluminós de la dama}

No obstant això, quan del cos que es despulla, a manera d'infracció màxima, arribem al cos nu de la dama, què passa amb aquest cos les descripcions del qual, totalment dominades pel topos, ens en diuen tan poca cosa?

Com ja hem pogut veure, la dama és blanca, amb la blancor ideal que exigeix la seva posició social i que no poden mai assolir les pastores, cremades pel sol, 
també per exigència de la seva condició rústica. Ja en un estadi previ, encara al moment de la projecció imaginària, Bernart diu:

Qui ve sas belas faissos
ab que mia vas se atraih,
pot be saber atrasaih
que sos cors es bels e bos
e blancs sotz la vestidura
(eu non o dic mas per cuda)
que la neus, can ilh es nuda,
par vas lei brun'et escura
(I6, vv. 33-40)

[Qui contempla el seu bell rostre, amb el qual m'ha atret cap a ella, pot comprendre immediatament que el seu cos és bell i bo i blanc sota el seu vestit (jo només ho dic per suposició), perquè, quan ella està nua, la neu en comparació sembla bruna i fosca]

Amb aquest «per cuda», excusa la gosadia i alhora subratlla la distància, tot recordant-nos que la canso només ocupa l'espai previ, abans del fach (el fet, la consumació sexual de l'amor). I, de fet, la gran reivindicació del trobador sembla que sigui passar de la cuda al saber, és a dir obtenir l'accés a la contemplació de la dama. Recordem, però, que la contemplació completa inclou aquell plus en jos (és a dir, més avall) de què parla Bertran de Born, sempre més directe que el seu veí de Ventadorn. Seria interessant, per tant, sortir un instant de l'univers, tan controlat per una mena de policia del pensament, i fer un cop d'ull furtiu als contratextos més agosarats. Basti recordar les paraules brutals del trobador Mir Bernart a la tenso contra Sifre:

\section{Mas d'aysso dic -que soy verays- que tota drudaria nays d'aquel cap don pus se rescon. ${ }^{7}$}

[Però d'això dic -i sóc sincer- que tot amor neix d'aquell lloc que més s'amaga.]

En canvi, Bernart de Ventadorn afirma:

Molt me sap bo lo jorn qu'eu la remire la boch'e.ls olhs e.l fron e.ls mas e.ls bratz e l'autre cors que res non es a dire. (2I, vv. 19-2I)

7. Segueixo el text de Sansone (1992).
[Que feliç estic el dia que la contemplo, la boca, els ulls, les mans, els braços, i la resta del cos, que tota és perfecta.]

A aquesta noció extraordinària de «l'autre cors»,, Bertran de Born, més explíitit, hi oposa:

Ren de beutat non galia

ni.n fai nuilla fantaumia

lo joios,

joves, gens cors amoros;

e genssa, qui la deslia;

et on hom plus n'ostaria

garnizos,

plus en seria envejos,

que la nuoig fai parer dia

la gola, e quiln vezia

plus en jos,

totz lo mons en gensaria.

$(3, v v \cdot 25-36)$

[No enganya gens sobre la seva bellesa, ni en posseeix només l'aparença aquesta persona alegre, jove, graciosa i amable; ella esdevé encara més bella si hom la despulla. I com hom més li llevés els vestits, més la desitjaria, perquè el seu coll fa semblar la nit dia i per a qui pogués mirar més avall, tot el món s'embelliria.]

I, de fet, la llum, la resplendor, s'afegeix a la descripció de la blancor habitual de la dama, com veiem en un altre passatge de Bernart de Ventadorn on afirma que «sa beutatz alugora / bel jorn e clarzis noih negra» (I2, vv. 36-37) [La seva bellesa illumina el dia lluminós i fa clara la negra nit].

La dama és, doncs, una dona de carn i ossos, amb un cos que els trobadors descriuen com a gras, len, delgat (i amb l'adjectiu gras, es tracta ben bé de la carn que es descriu, perquè la domna no s'escapa dels cànons de bellesa de l'època), però la seva corporalitat, tan material, no li impedeix de participar en un altre univers més elevat. La contemplació d'aquesta dama, en certa manera dual, sembla ben bé l'objectiu final de l'erotisme, si no de l'amor. Perquè la fin'amor adúltera, convé no oblidar-ho, no s'acaba en la foscor de la complicitat sinó en una doble llum, que prové tant de l'exterior com de l'interior. De la llum exterior ens en parla Arnaut Daniel amb la imatge d'una làmpada:
uns rics covens don tan gran joi atendi
quel sieu bel cors, baizan, rizen descobra
e quel remir contral lum de la lampa
(I, vv. 38-40) 


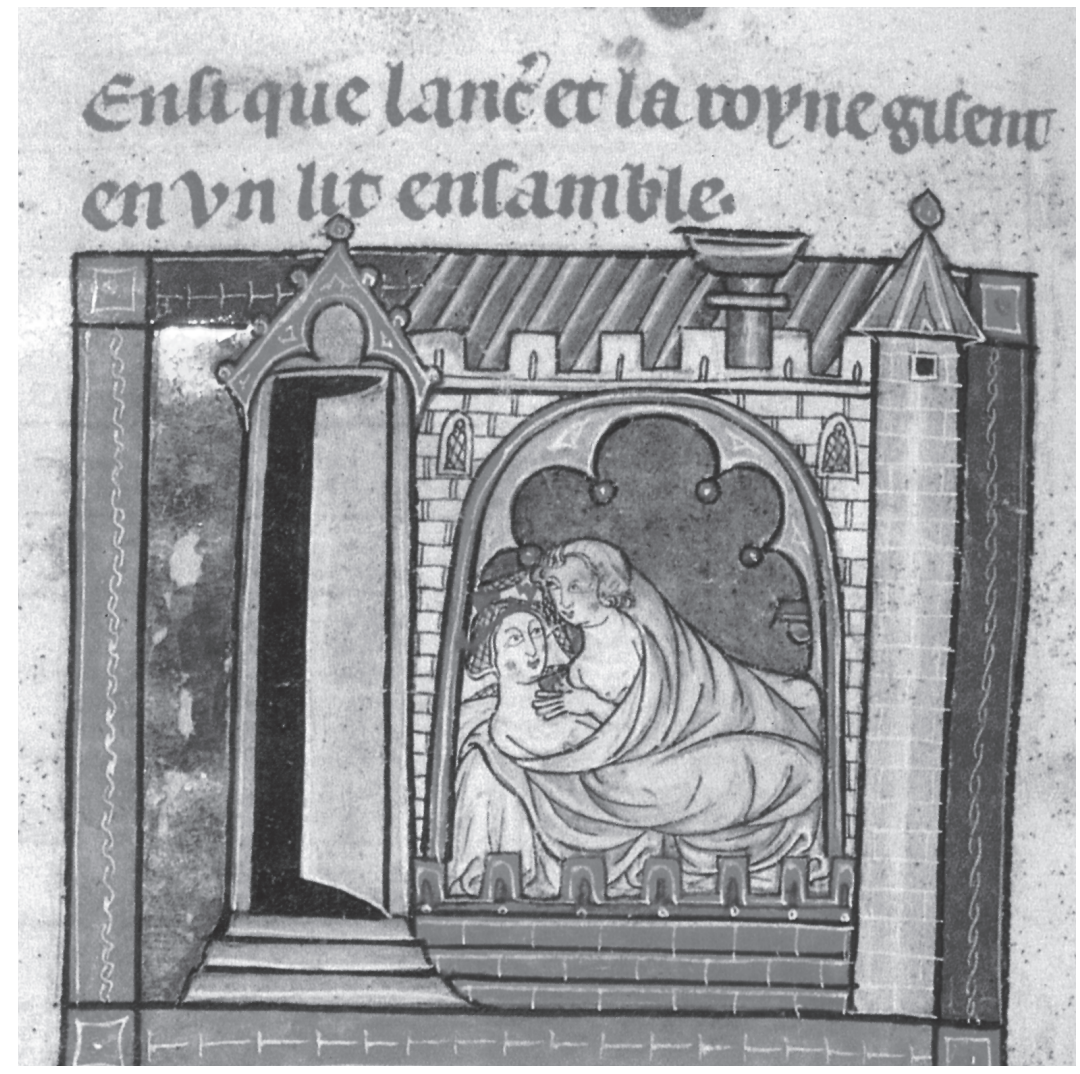

Lancelot i Ginebra consumen l'amor (Lancelot-Graal, British Library, Londres) coses que existeixen en l'ordre universal]» (Guida 1996: 56).

Això ens permet veure sota una altra llum, a nosaltres també, aquest cos blanc i lluminós, sovint relacionat amb la neu, com ara en aquests versos de Bernart de Ventadorn: «cors blanc tot atretal / com la neus a Nadal» (I7, vv. 3738) [cos d'una blancor comparable a la neu per Nadal]. La comparació sembla que el resguardi de qualsevol altra possessió que no sigui la contemplació. Aquest plus en jos o autre cors misteriós, portador de la llum, que condueix a una contemplació extàtica, deixa al trobador sense veu i, alhora, a l'amant sense acte.

L'última paraula la té Mir Bernart, pronunciada amb gran escàndol, més o menys simulat, de Sifre, que li fa exclamar: «Mir Bernart, ben es enportus, / car no'm respondes ab motz clus»y (vv. 15-16) [Mir Bernat, sou ben inoportú en no respondre'm amb mots dissimulats]. L'ultima paraula

[una rica promesa de la qual n'espero aquesta joia tan gran: que ella descobreixi el seu bell cos entre petons i rialles i que jo la contempli contra la llum de la làmpada]

D'un costat, doncs, la llum provinent de l'exterior, com al desig expressat per Bernart de Ventadorn, que en el seu somni s'ocupa prou de collocar la seva dama «en leih, sotz fenestral», al llit sota la finestra; de l'altre, la llum interior que irradia el cos de la dama. És impossible no recordar les paraules de Saverio Guida: «Els homes de l'Edat Mitjana sentien una inclinació particular cap a tot allò que era clar, lluminós, resplendent [...] i preuaven de manera especial tot allò que els semblava blanc, radiant i transparent. Sant Bonaventura havia afirmat que 'lux est pulcherrimum et delectabilissimum et optimum inter corporalia' [la llum és la cosa més bella, delectable i millor entre tot allò que és corporal] i, cap a mitjans del segle XIII, l'anònim autor del tractat De intellegentiis se'n feia ressò declarant que 'perfectio omnium eorum quae sunt in ordine universo est lux' [la llum és la perfecció de totes les és, doncs, per al trobador que es presenta com a amant sense vergonya del con, i que li retreu clarament i amb gosadia al seu adversari que sigui tan poc exigent: «avetz sel laysat e gurpit, / per quell bon drut son esbaït / e cascus n'a.l cor jauzion» (vv. 47-49) ${ }^{8}$ [Vós heu deixat i abandonat allò que esbalaeix els veritables amants i a tots els omple el cor de joia]. Aquest esbalaïment, aquest èxtasi que omple el cor de joia, em semblen una bona definició de la finalitat última de la fin'amor.

Traducció de MARINA NaVÀS

\footnotetext{
8. M'he permès de modificar 'sel' en comptes de la tria 'fel' de l'edició, per motius paleogràfics evidents.
} 


\section{Bibliografia citada}

BEC, Pierre, 1992: «Le corps et ses ambiguïtés chez Bernard de Ventadour et quelques autres troubadours», Le corps et ses énigmes au Moyen Age, dir. B. Ribémont, Caen: Paradigme, 1993.

BEC, Pierre, 2004: Le comte de Poitiers, premier troubadour. A l'aube d'un verbe et d'une érotique, $2 \mathrm{a}$ ed., Montpeller: Centre d'Études Occitanes.

GoulRan, Gérard, 1989: L'amour et la guerre. L'œuvre poétique de Bertran de Born, Aix-en-Provence - Marseille:

Publications de l'Université de Provence.
LAZAR, Moshé, 1966: Bernard de Ventadour, troubadour du XII siècle. Chansons d'amour, édition critique avec traduction, introduction, notes et glossaire, París: Klincksieck.

PARDucCl, Amos, 1920: «Bonifazio di Castellana», Romania, $46,478-511$.

Riquer, Martí de, 1994: Arnaut Daniel, poesías; traduccion, introducción, y notas, Barcelona: Quaderns Crema.

SANSONE, Giuseppe E., 1992: I trovatori licenziosi, Milà: ES

GuIDA, Saverio, 1996: Primi approci a Uc de Saint-Circ, Soveria Mannelli: Rubbertino.

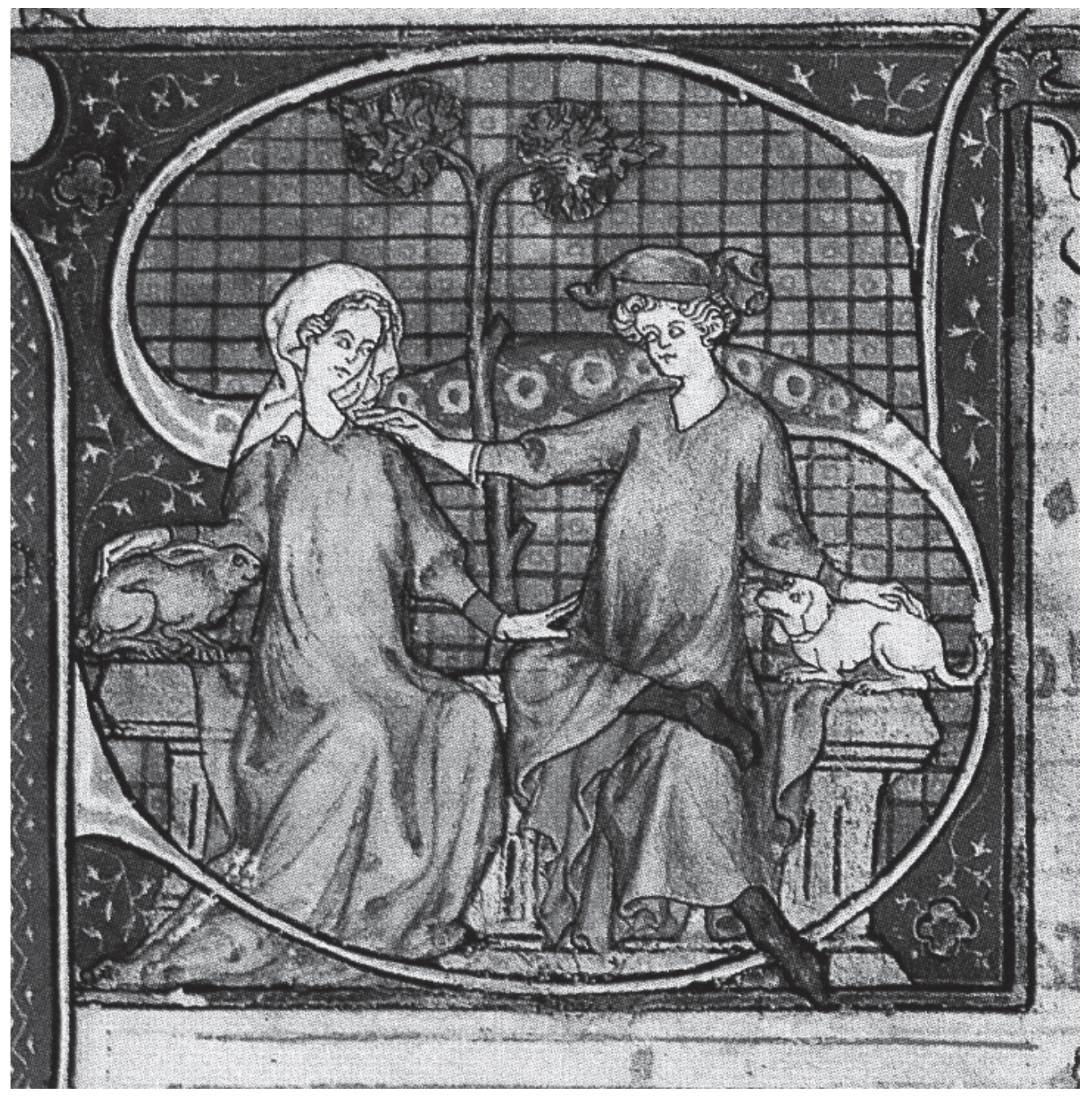

Carícies dels enamorats (Bibliothèque universitaire de médicine, Montpeller) 